\title{
Correction to: Cadmium exposure alters steroid receptors and proinflammatory cytokine levels in endothelial cells in vitro: a potential mechanism of endocrine disruptor atherogenic effect
}

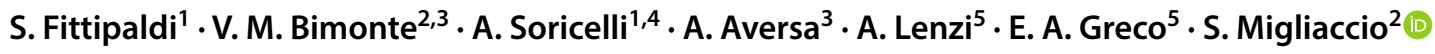

Received: 17 October 2018 / Accepted: 8 December 2018 / Published online: 19 December 2018

(c) Italian Society of Endocrinology (SIE) 2018

\section{Correction to: Journal of Endocrinological Investigation https://doi.org/10.1007/s40618-018-0982-1}

Unfortunately, the figure captions 4 and 6 were incorrectly published in the original publication. The complete correct captions are given below.

Figure 4 Cadmium modulation of AR-mediated signaling pathway. Representative blot which depicts AR and its phosphorylation at serine $308\left(\mathrm{PhAR}^{\mathrm{ser} 308}\right)$, GSK-3 $\beta$ and its phosphorylation at serine 9 (PhGSK-3 $\left.\beta^{\text {ser9}}\right)$ after $1 \mathrm{~h}$ of $\mathrm{Cd}$ exposure (a). Histograms represent the mean values of ratio of PhAR ${ }^{\mathrm{ser} 308}$ normalized over AR total protein level and the PhGSK- $3 \beta^{\text {ser9 }}$ level normalized to GSK-3 $\beta$ total protein content (b). Representative blot which depicts AR phosphorylation at serine 308 and AKT phosphorylation at serine 473 $\left(\mathrm{PhAKT}^{\mathrm{ser} 473}\right)$ in HUVECs after $1 \mathrm{~h} \mathrm{CdCl}_{2}(10 \mu \mathrm{M})$ treatment, in the presence of GSK-3 $\beta$ inhibitor, AR-A014418 $(10 \mu \mathrm{M})(\mathbf{c})$. Histograms represent the mean values of ratio of $\mathrm{PhAR}^{\mathrm{ser} 308}$ normalized over AR total protein and PhAKT ${ }^{\text {ser473 }}$ over total AKT (d). Effect of $\mathrm{CdCl}_{2}$ with or without DHT on HUVECs proliferation (e). Cells were incubated with or without $\mathrm{CdCl}_{2}(10 \mu \mathrm{M})$, DHT $(0.01 \mu \mathrm{M})$ or $\mathrm{CdCl}_{2}$ in the presence of DHT for 24 and $48 \mathrm{~h}$. Number of viable cells was quantified using the MTS assay. Results are presented as mean \pm SD of three separate experiments. ${ }^{* *} p \leq 0.01$ and $* p \leq 0.05$ vs vehicle-treated cells; ${ }^{\S} p \leq 0.05$ vs $10 \mu \mathrm{M} \mathrm{CdCl}_{2}$-treated cells.

Figure 6 Effect of ER $\beta$ blockage on proinflammatory cytokines expression. RT-qPCR showing TNF $\alpha(\mathbf{a})$, IL-6 (b), and IL-8 (c) mRNA levels of HUVECs cells exposed to $\mathrm{CdCl}_{2}(10 \mu \mathrm{M})$ or E2 $(0.01 \mu \mathrm{M})$ in the presence or absence of PHTPP $(5 \mu \mathrm{M})$, a selective inhibitor of ER $\beta .^{*} p \leq 0.05$ and ${ }^{* *} p \leq 0.01$ vs vehicle treated cells; ${ }^{\S} p \leq 0.01$ and ${ }^{\S} p \leq 0.05$ vs $10 \mu \mathrm{M} \mathrm{CdCl}_{2}$-treated cells.

The original article can be found online at https://doi.org/10.1007/ s40618-018-0982-1.

S. Migliaccio

silvia.migliaccio@uniroma4.it

IRCCS SDN, Naples, Italy

2 Department of Movement, Human and Health Sciences, Section of Health Sciences, "Foro Italico" University of Rome, Largo Lauro De Bosis 6, 00195 Rome, Italy

3 Department of Experimental and Clinical Medicine, Magna Græcia University, Catanzaro, Italy

4 Department of Motor Sciences and Healthiness, University of Naples Parthenope, Naples, Italy

5 Department of Experimental Medicine, Section of Medical Pathophysiology, Endocrinology and Nutrition, "Sapienza" University of Rome, Rome, Italy 